\title{
VALIDATION OF A BIOANALYTICAL REVERSE-PHASE HIGH-PERFORMANCE LIQUID CHROMATOGRAPHIC METHOD FOR THE QUANTITATION OF NYSTATIN IN AN ANIMAL MODEL AFTER INTRANASAL IN SITU GEL ADMINISTRATION
}

\author{
KAZI MARZUKA*, DEHGHAN MOHAMED HASSAN \\ Department of Pharmaceutics, Y.B. Chavan College of Pharmacy, Dr. Rafiq Zakaria Campus, Aurangabad, Maharashtra, India. \\ Email: marzi345@gmail.com
}

Received: 27 July 2020, Revised and Accepted: 02 September 2020

ABSTRACT

Objective: The aim of the study was to develop and validate a bioanalytical reverse-phase high-performance liquid chromatographic (HPLC) method for the estimation of nystatin in rat plasma after intranasal administration.

Methods: The reversed-phase HPLC system was equipped with a Luna C18 column, the mobile system comprised of methanol, water, and dimethylformamide $(55: 30: 15)$ and the flow rate was set at $0.9 \mathrm{ml} / \mathrm{min}$.

Results: The elution time for nystatin was $4.096 \pm 0.025 \mathrm{~min}$. The calibration curves constructed in rat plasma were linear from 0.25 to $50 \mu \mathrm{g} / \mathrm{ml}$. The lower limit of quantification (LOQ) was found to be $0.25 \mu \mathrm{g} / \mathrm{ml}$. The standards for accuracy and precision of the intra- and inter-day variation studies were in the acceptable ranges as per the FDA guidelines.

Conclusion: The LOQ value determined by the proposed method was noted to be satisfactory for inspecting the plasma pharmacokinetics of nystatin in rats' post-administration of a nasal in situ gelling liquid crystalline precursor formulation in an in vivo study.

Keywords: Nystatin, Rat plasma, Intranasal in situ gel, Reverse-phase high-performance liquid chromatographic, Validation.

(c) 2020 The Authors. Published by Innovare Academic Sciences Pvt Ltd. This is an open access article under the CC BY license (http://creativecommons. org/licenses/by/4. 0/) DOI: http://dx.doi.org/10.22159/ajpcr.2020.v13i10.39229

\section{INTRODUCTION}

The polyene class of antifungals such as nystatin, natamycin, and amphotericin B has a wide action against broad spectrum of fungi species such as Candida, Cryptococcus, Histoplasma, Blastomyces, and Aspergillus [1,2]. Initial efforts in accomplishing free drug administration have led to dose-limiting toxicity. It has been reported that nystatin can be loaded into liposomes and administered intravenously to reduce toxicity while retaining its antifungal activity [3-6]. At present, there are no drug therapies of nystatin that can be used to treat non-invasive nasal aspergillosis, except for nasal irrigation $[7,8]$. Moreover, using permeation enhancers, the intranasal delivery of nystatin can perhaps be used to achieve drug concentration in systemic circulation, thus can be applied in treatment of systemic fungal infections [9]. The mucociliary clearance plays an important role in depletion of the drug; therefore, mucoadhesive formulation that enhances residence time and control drug release can be deployed to overcome these inadequacies [10]. Biopharmaceutical performance of these newer formulations has to be assessed and necessitates the development of satisfactory analytical methodologies. In comparison to the previous methods for the detection of nystatin in plasma and tissues, our technique utilizes lower flow rate, shorter retention time, and an uncomplicated mobile phase composition which is trouble free to prepare and is neutral thus avoids instability of nystatin which is observed at low pH [11-14]. Moreover, the developed method was validated in accordance with the International Council on Harmonization. Finally, to estimate the intranasal in vivo performance of the in situ gelling liquid crystalline precursor system has led to the development of a suitable highperformance liquid chromatographic (HPLC) an analytical method that is accounted for here.

\section{METHODS}

Reagents and chemicals

Nystatin was obtained as a kind gift sample from Glenmark Limited (Mumbai, India). Plasma was separated from whole blood collected from healthy male Wistar rats. HPLC grade solvents were procured from Merck (India) such as methanol $(\mathrm{MeOH})$, acetonitrile $(\mathrm{AcN})$, and dimethylformamide (DMF). Deionized was used in all experiments.

\section{Chromatographic system}

HPLC device (Waters HPLC, Alliance) with photo array detector (Waters 2996) set at a wavelength of $305 \mathrm{~nm}$ was used. The system was equipped with a Waters 1525 pump, an autosampler Waters 717 plus, and a column heater Waters 1500 series. The analytical column fixed in the device was a reversed-phase Luna C18 (Phenomenex) with an internal diameter of $150 \mathrm{~mm} \times 4.6 \mathrm{~mm}$ and with a $5 \mu \mathrm{m}$ particle size. The column oven was kept at $25^{\circ} \mathrm{C}$ and confined by a Security Guard precolumn. The mobile phase comprised $\mathrm{MeOH}: \mathrm{H}_{2} \mathrm{O}: \mathrm{DMF}$ (55:30:15, v/v/v). Elution was executed isocratically $\left(25^{\circ} \mathrm{C}\right)$ at a well maintained flow rate of $0.9 \mathrm{ml} / \mathrm{min}$ and the run time was fixed for $10 \mathrm{~min}$. The mobile phase was degassed by vacuum ahead of use. A $0.45 \mu \mathrm{m}$ (Millipore Durapore) filter membrane was employed for the filtration of mobile the phase.

\section{Preparation of standard solutions}

Bulk nystatin was dissolved in $\mathrm{MeOH}$ by the aid of ultrasonication to obtain a standard stock solution of $500 \mu \mathrm{g} / \mathrm{ml}$. Further dilution was made to the standard stock solution to prepare working standards of $50 \mu \mathrm{g} / \mathrm{ml}, 5 \mu \mathrm{g} / \mathrm{ml}$, and $0.25 \mu \mathrm{g} / \mathrm{ml}$. Thereafter, separate stock solutions were made for standard curves and quality control (QC) samples. Sixpoint calibration curves with lower range $0.25-1.5 \mu \mathrm{g} / \mathrm{ml}$ and higher range $1.5-50 \mu \mathrm{g} / \mathrm{ml}$ were used for quantification of the drug in plasma. The calibration standards were prepared by adding stock solution 10$50 \mu \mathrm{l}$ and adding plasma to make up the total volume to $1000 \mu \mathrm{L}$.

\section{Sample preparation}

Nystatin was extracted from plasma by adding HPLC grade $\mathrm{MeOH}-$ $\operatorname{AcN}(1: 1)$ in the ratio of $1: 2 \mathrm{v} / \mathrm{v}$ and incubating at $2-8^{\circ} \mathrm{C}(30 \mathrm{~min})$ in polypropylene tubes. Thereafter, the sample was subjected to a twostep centrifugation cycle. The first cycle was applied for $10 \mathrm{~min}$ at 2000 
g, the supernatant was separated and added to a new tube followed by the application of the second cycle for $4 \mathrm{~min}$ at $10,000 \mathrm{~g}$. A sample of $400 \mu \mathrm{l}$ of supernatant was filtered through a $0.22 \mu \mathrm{m}$ Durapore filter and further centrifuged for $4 \mathrm{~min}$ at $4000 \mathrm{~g}$. A $20 \mu \mathrm{l}$ of aliquot was injected into the analytical column.

\section{Validation parameters}

Linearity

Calibration curves were constructed in six-point replicate sets and analyzed, repetitively, for 2 consecutive days. The curves were generated by linear regression analysis of the summing up of the peak areas of the two main peaks of nystatin versus concentrations. The determination coefficients $\left(\mathrm{r}^{2}\right)$, standard deviations (SD), and coefficient of variance $(\% \mathrm{CV})$ were calculated on each of 2 days. The linearity was also evaluated by plotting the interposed concentrations against their spiked concentrations.

\section{Accuracy and precision}

The proposed method's accuracy and precision were assessed by performing six replicate analyses of QC samples at intraday and interday. The concentrations were selected at three levels of low and high range the calibration curves, that is, lower QC (LQC), middle QC (MQC), and higher QC (HQC). The \% accuracy of the system was calculated, whereas the precision was attributed to the \%CV [15-19].

\section{Lower limit of quantification (LOQ)}

LOQ is described as the lowest standard concentration in an analytical study that can be computed with a deviation of the definite concentration and a coefficient of variation of precision $<20 \%$. Six replicate sets of samples at the lowest concentration were prepared and assayed to determine $\% \mathrm{CV}$ and percentage accuracy $[15,16]$.

\section{Specificity}

Blank plasma, standard drug solution, and sample formulation spiked with the known concentration of drug were injected in triplicate into HPLC system to determine method specificity. The chromatograms were observed for any interference at the retention time of the analyte peak. Percentage assay difference between mean of spiked sample results and mean of the method precision was calculated $[15,16]$.

\section{Recovery}

To scrutinize the extraction competence of the proposed method, a set of six samples at three QC levels of the lower and higher range calibration curves, that is, LQC, MQC, and HQC were prepared by spiking nystatin in plasma and further processed (pre-extraction). Likewise, another set of plasma samples were firstly prepared and thereafter spiked, that is, post-extraction at the three QC levels of the lower and higher range calibration curve. The effectiveness of extraction for the analyte was calculated by the ratios of the peak areas of pre-extraction samples to post-extraction samples $[15,16]$.

\section{Stability}

The stability of nystatin was tested for both processes and storage stability. For the determination of process stability, QC samples at the two concentration levels, that is, lower range $(1.25$ and $0.5 \mu \mathrm{g} / \mathrm{ml})$ and higher range (20 and $5 \mu \mathrm{g} / \mathrm{ml}$ ) were studied. The samples were run immediately after preparation and yet again the same samples were stored at $2-8^{\circ} \mathrm{C}$, later analyzed after a time period of $12 \mathrm{~h}$ and $24 \mathrm{~h}$. Similarly, storage stability was also estimated at the above-mentioned concentration, the samples were stored below $-20^{\circ} \mathrm{C}$, and the testing was performed at three timelines (baseline, 1 month, and 3 months). Drug stability was also determined after freeze and thaw cycles.

\section{Application - pharmacokinetic studies}

Male Wistar rats (250-300 g) were procured from Wockhardt Research Centre (Aurangabad, India). All the rats were inhabited in a light controlled room $\left(22 \pm 2^{\circ} \mathrm{C}\right.$ and $\left.\mathrm{RH} 55 \pm 5 \%\right)$. The experimental protocol (CPCSEA/IAEC/P'ceutics-30/2016-17/125) concerning the animal study was approved by the IAE committee of Y.B. Chavan College of Pharmacy, Aurangabad. The dose of NYS administered was $8 \mathrm{mg} / \mathrm{kg}$ as a single dose. Nasal administration was performed with a $20 \mu \mathrm{l}$ micropipette to instil $20 \mu \mathrm{l}$ of the in situ gelling fluid liquid crystalline precursor into each nostril at a time until a total of $60 \mu \mathrm{l} \mathrm{had}$ been instilled [20]. This spaced instillation was intended to minimize the overflow into the gastrointestinal tract. Blood samples of $0.5 \mathrm{ml}$ each were withdrawn into $1.5 \mathrm{ml}$ heparinized PE tubes from the retroorbital plexus at $15,30,45,60,90,120,150,180,240$, and $360 \mathrm{~min}$ immediately after dosing of the formulation. The plasma was separated from the whole blood sample by centrifugation at $13,000 \mathrm{rpm}$ for 10 min, thereafter stored at below $-20^{\circ} \mathrm{C}$ until the samples were analyzed.

\section{RESULTS AND DISCUSSION}

\section{Reverse-phase (RP)-HPLC analysis}

The chromatograms of blank rat plasma and plasma spiked with bulk nystatin $50 \mu \mathrm{g} / \mathrm{ml}$ are presented in Fig. 1 .

It is well documented that nystatin is a lyophobic drug and hence its solubility at room temperature in an aqueous solvent is practically insoluble while is soluble in organic solvents such as $\mathrm{MeOH}$, ethanol, AcN, and DMF [21]. It is reported elsewhere that the solubility of nystatin in polar solvents can be substantially increased in the presence of 10-20\% water $[21,22]$. In the present study, a mobile phase system comprising $\mathrm{MeOH}$, water, and DMF was prepared in volume ratio 55:30:15. It has been well established elsewhere the same mobile phase system was applied in the liquid chromatographic determination of bulk nystatin in various pharmaceutical preparations such as creams, ointments, oral suspensions, and topical powders [12]. The above-described system although studied for pharmaceutical formulations was not validated and applied for the bioanalytical analysis of nystatin in plasma and in varied body fluids such as saliva and tissues. The retention time for the major and minor nystatin peaks in the pharmaceutical formulation by the mentioned mobile phase in earlier studies was documented as $11.7 \mathrm{~min}$ and $17.5 \mathrm{~min}$, respectively [12]. In another study, wherein the mobile phase system composed of $10 \mathrm{mM}$ sodium phosphate, $1 \mathrm{mM}$ ethylenediaminetetraacetic acid, $30 \% \mathrm{MeOH}$, and $30 \% \mathrm{AcN}$ was applied in the bioanalytical analysis of nystatin in rabbit plasma; the retention time for the major and minor peaks were found to elute at 7.5-8.5 and 9.5-10.5 min, respectively [23].

The application of the mobile phase comprising $\mathrm{MeOH}$, water, and $\mathrm{DMF}$ (55:30:15) leads to a reduction in tailing factor and was within the acceptable limit (United States Pharmacopoeia (USP) tailing factor $<2$ ) with high-quality resolution and improved peak symmetry with lower retention time. The flow rate was studied at $0.3,0.6,0.9$, and $1.2 \mathrm{ml} /$ min. Lower flow rates resulted in longer retention time and at higher flow rate, peak poor resolution was seen. It was noted that at a flow rate of $0.9 \mathrm{ml} / \mathrm{min}$, the retention time for the major and minor peak was $4.096 \mathrm{~min}$ and $4.470 \mathrm{~min}$, respectively. The result for system suitability parameters obtained is highlighted in Table 1.

The minor peak of nystatin is assigned to its isomer formed in biological fluids and was observed only at concentrations greater than $5 \mu \mathrm{g} / \mathrm{mL}$. Further, the quantification was based on sum of the peak area concentration of both the peaks.

\section{Validation parameters}

Linearity and range

The data pertaining to the calibration curve are presented in Tables 2 and 3 . The curves were plotted in two plots form a low range

Table 1: Data for system suitability parameters

\begin{tabular}{ll}
\hline Parameter & Observations \\
\hline Retention time & $4.096 \pm 0.025 \mathrm{~min}$ \\
Theoretical plates & $4627 \pm 76.57$ \\
Peak symmetry & $1.10 \pm 0.015$ \\
\hline
\end{tabular}

$*_{\mathrm{n}}$ is number of replicates, $\mathrm{n}=6$ 


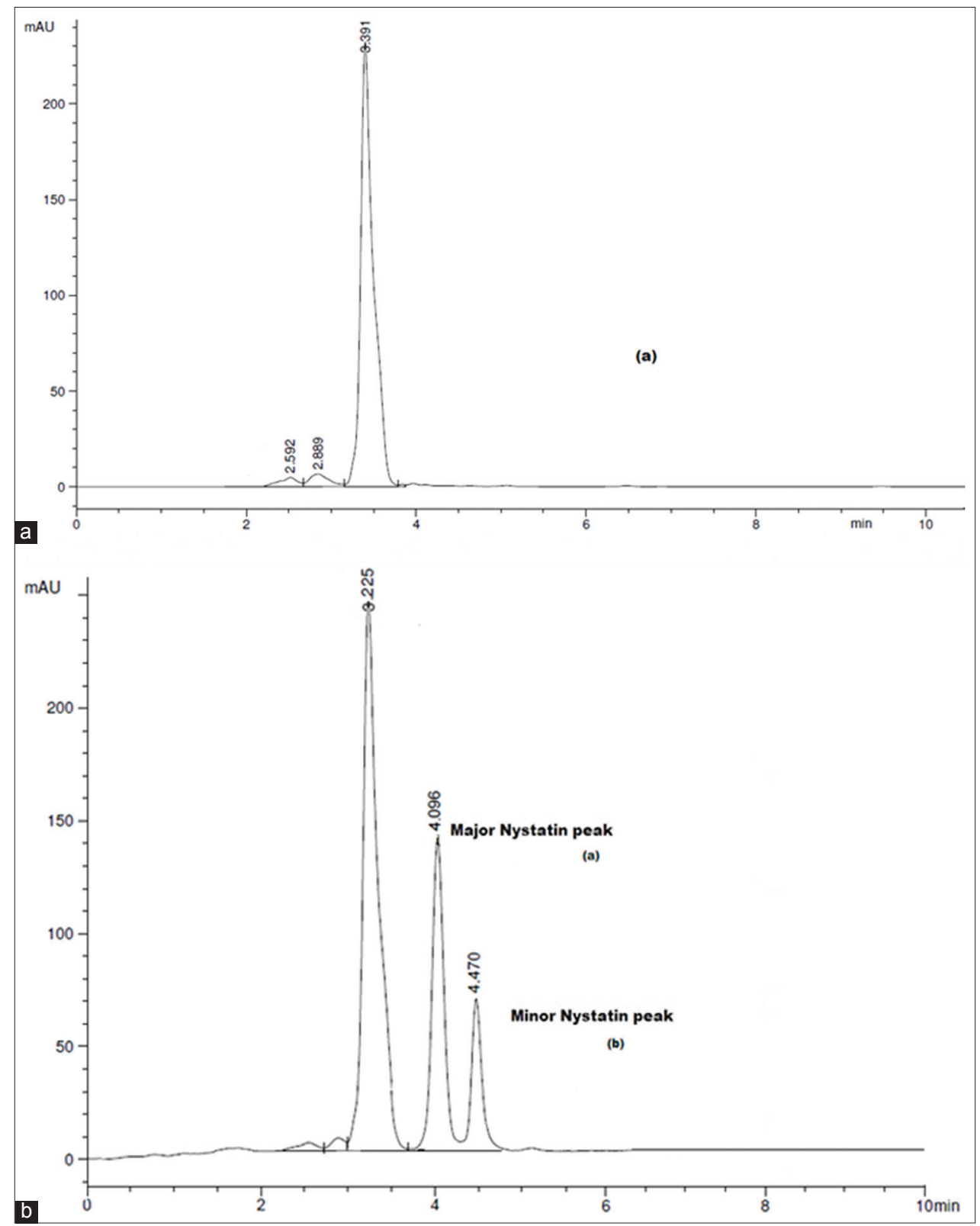

Fig. 1: High-performance liquid chromatographic chromatogram of (a) blank plasma at 3.39 min (b) extracted rat plasma spiked with bulk nystatin showing major peak at $4.096 \mathrm{~min}$ and minor peak at $4.470 \mathrm{~min}$

Table 2: Calibration curve specifications for nystatin in rat plasma

\begin{tabular}{lllll}
\hline Day & Curve & Slope & Intercept & $\mathbf{r}^{2}$ \\
\hline 1 & 1a & 15101 & 693.4 & 0.996 \\
2 & 2a & 15378 & 340.2 & 0.999 \\
1 & 1b & 15678 & 462.1 & 0.999 \\
2 & 2b & 15478 & 773.9 & 0.998 \\
\hline
\end{tabular}

* 1 a and $1 \mathrm{~b}$ lower concentration range calibration curve at day 1 and day 2 , respectively. $1 \mathrm{a}$ and $1 \mathrm{~b}$ higher concentration range calibration curve at day 1 and day 2 , respectively

and high range curves since the exact concentration range of drug in plasma was not clear before conducting pharmacokinetic studies. Moreover, a single calibration across a wider range could hinder the accuracy and precision of the extreme values in the range. The calibration curve exhibited linearity with $r^{2} \geq 0.995$ over the range of estimation, that is, $0.25-50 \mu \mathrm{g} / \mathrm{ml}$.

\section{Accuracy and precision}

A methods precision is expressed in observation to the $\% \mathrm{CV}$ of replicates and for it to be in an acceptable range, all concentration values should be within $\pm 15 \%$. The precision of the method was assessed for intraday as well for interday repeatabilities and the data are presented in Table 4. For both studies, \%CV was found to be lower than 5\% suggestive of satisfactory repeatability of the proposed method. The accuracy of the proposed method was determined by the nearness of the difference between the mean of the calculated values from the factual value. The values were considered to be acceptable if the actual value at all concentrations was within $\pm 15 \%$. The accuracy standard in intra- and inter-day precision studies at lower and higher concentration range was within the acceptable confines.

\section{Lower $L O Q$}

LOQ was defined as the lowest amount of nystatin that could be detected in the plasma at a precision of $\leq 20 \%$ and the accuracy, that 
Table 3: Calibration curve data representing concentration of nystatin in rat plasma

\begin{tabular}{llllll}
\hline Calibration curve & Spiked concentration $(\boldsymbol{\mu g} / \mathbf{m l})$ & Mean calculated concentration $(\boldsymbol{\mu g} / \mathbf{m l})$ & SD & CV $(\%)$ & Accuracy $(\%)$ \\
\hline Higher range & 50 & 50.47 & 0.692 & 1.371 & 105.75 \\
& 40 & 40.58 & 0.879 & 2.166 & 101.59 \\
& 32.5 & 32.685 & 0.776 & 2.374 & 98.026 \\
& 21.85 & 21.83 & 0.836 & 3.827 & 98.281 \\
& 11.5 & 11.48 & 0.462 & 4.028 & 94.130 \\
Lower range & 5.85 & 5.77 & 0.282 & 4.902 & 96.265 \\
& 1.48 & 1.45 & 0.105 & 7.228 & 100.888 \\
& 0.25 & 0.269 & 0.017 & 6.230 & 97.968 \\
& 0.48 & 0.487 & 0.059 & 12.156 & 98.638 \\
& 0.76 & 0.953 & 0.035 & 4.766 & 99.855 \\
& 1.97 & 1.181 & 0.039 & 4.112 & 99.922 \\
& 1.25 & 1.503 & 0.053 & 4.448 & 100.569 \\
& 1.56 & 1.816 & 0.048 & 3.241 & 101.466 \\
\end{tabular}

*SD: Standard deviation, $\mathrm{n}=12$, CV: Coefficient of variance

Table 4: Intraday and interday precision data for nystatin in rat plasma

\begin{tabular}{|c|c|c|c|c|c|}
\hline \multirow[t]{2}{*}{ Calibration curve } & \multirow[t]{2}{*}{ Spiked level $(\mu \mathrm{g} / \mathrm{ml})$} & \multicolumn{2}{|c|}{$\%$ Accuracy } & \multicolumn{2}{|l|}{$\% \mathrm{CV}$} \\
\hline & & Intraday & İnterday & Intraday & İnterday \\
\hline \multirow[t]{3}{*}{ Lower range } & LQC (0.25) & 92.18 & 91.64 & 4.56 & 2.94 \\
\hline & MQC (1) & 94.203 & 97.147 & 2.721 & 1.702 \\
\hline & HQC (1.75) & 89.266 & 92.462 & 3.682 & 3.834 \\
\hline \multirow[t]{3}{*}{ Higher range } & LQC (5) & 94.729 & 95.211 & 2.435 & 2.382 \\
\hline & MQC (20) & 95.088 & 96.173 & 2.664 & 2.422 \\
\hline & HQC (50) & 96.016 & 95.920 & 4.182 & 4.041 \\
\hline
\end{tabular}

${ }^{*} n$ is number of replicates, $n=6, C V$ : Coefficient of variance. LQC: Lower quality control, MQC: Middle quality control, HQC: Higher quality control

is, the difference between the mean of the calculated values from the factual value was within $\pm 15 \%$. Lowest standard drug concentration was prepared in six replicates $(0.25 \mu \mathrm{g} / \mathrm{ml})$ and was analyzed to determine LOQ. At the estimated LOQ value, the \%CV was 9.372 with an accuracy of $105.4 \%$.

\section{Specificity}

To substantiate whether bulk nystatin could be employed as a reference standard to analyze nystatin loaded in situ gelling formulation, normal rat plasma was spiked with in situ gelling formulation at three different concentrations 5.2, 10.4, and $20.8 \mu \mathrm{g} / \mathrm{ml}$. Plasma samples were extracted, assayed using a high range calibration curve constructed using bulk nystatin. The accuracies obtained at these concentrations were found to be $96.13 \%, 98.81 \%$, and $97.34 \%$, respectively. The precision as estimated by the coefficient of variation of the mean was noted to be $2.545 \%, 1.444 \%$, and $3.350 \%$, respectively. No interference was seen with rat plasma components. Thus, the method was found to be specific for estimation of nystatin from the prepared in situ gelling formulation as the $\% \mathrm{CV}$ was $<5 \%$.

\section{Recovery}

The recovery data for nystatin in rat plasma is presented in Table 5 . The higher values of recovery of nystatin assure that almost complete extraction of the drug was achieved and an insignificant amount of drug remained in the plasma after plasma protein extraction step. Lower values of \%CV point out that the developed method demonstrated a higher scales of extraction efficiency.

\section{Stability}

In general, the analysis of the biological samples for drug content is not undertaken instantaneously after sample collection and preparation. As a result, it is imperative to determine if the drug is constant throughout the study time. Process, as well as storage stability, was determined by extracting four sets of plasma control of which two were of the lower range $(1.25$ and $0.5 \mu \mathrm{g} / \mathrm{ml})$ and the
Table 5: Recovery data for nystatin in rat plasma

\begin{tabular}{llll}
\hline Calibration curve & Spike level $\boldsymbol{\mu g} / \mathbf{m l}$ & \% recovery & CV (\%) \\
\hline Lower range & LQC (0.25) & 92.319 & 5.42 \\
& MQC (1) & 91.038 & 3.15 \\
Higher range & HQC (1.75) & 91.295 & 3.047 \\
& LQC (5) & 94.84 & 2.348 \\
& MQC (20) & 95.101 & 2.672 \\
& HQC (50) & 96.019 & 4.193 \\
\hline
\end{tabular}

${ }^{*} \mathrm{n}$ is the number of replicates, $\mathrm{n}=6, \mathrm{CV}$ : Coefficient of variance. LQC: Lower quality control, MQC: Middle quality control, HQC: Higher quality control

other two of the higher range (20 and $5 \mu \mathrm{g} / \mathrm{ml})$. The samples were run immediately after preparation and yet again the same samples were stored at $2-8^{\circ} \mathrm{C}$ later analyzed after a time period of $12 \mathrm{~h}$ and $24 \mathrm{~h}$, the results are depicted in Table 6. The percentage relative SD was within $4 \%$. The data for storage stability are also presented in Table 6. The plasma samples spiked with nystatin were stored at a temperature below $-20^{\circ} \mathrm{C}$. The $\% \mathrm{CV}$ for all the sample set range was within $6 \%$. Thus, nystatin was found to be stable in plasma when stored below $-20^{\circ} \mathrm{C}$ for at least 3 months. Furthermore, the stability of the samples was also tested post three freeze-thaw cycles. The results indicated that thawing and refreezing had the slightest outcome on the precision and accuracy of the findings (\%CV was within $6 \%$ )

\section{Application - pharmacokinetic studies}

Plasma concentration versus time profile curve for the nasally administered in situ gelling liquid crystalline precursor formulation of nystatin in Wistar rats is presented in Fig. 2. A single dose of 8 $\mathrm{mg} / \mathrm{kg}$ was administered in rats; the quantification of nystatin was performed based on the above-validated method. The maximum concentration in plasma $\left(\mathrm{C}_{\max }\right)$ and the time required to achieve maximum concentration in plasma $\left(\mathrm{T}_{\max }\right)$ was found to be $11.37 \mathrm{ug} / \mathrm{ml}$ and $30 \mathrm{~min}$. 
Table 6: Process and storage stability data for nystatin in rat plasma

\begin{tabular}{lllll}
\hline Process stability & \multicolumn{3}{l}{$l$} \\
\hline Range & $\begin{array}{l}\text { Spiked } \\
\text { concentration } \\
(\boldsymbol{\mu g} / \mathbf{m l})\end{array}$ & $\begin{array}{l}\text { Obtained concentration }(\boldsymbol{\mu g} / \mathbf{m l}) \\
\text { (mean } \pm \text { SD) }\end{array}$ \\
\cline { 2 - 5 } & Baseline & $\mathbf{1 2} \mathbf{~ h}$ & $\mathbf{2 4} \mathbf{~ h}$ \\
\hline Higher & 20 & $19.10 \pm 0.35$ & $18.86 \pm 0.09$ & $18.98 \pm 0.2$ \\
& 5 & $5.054 \pm 0.049$ & $5.136 \pm 0.072$ & $5.08 \pm 0.117$ \\
Lower & 1.5 & $1.534 \pm 0.032$ & $1.528 \pm 0.021$ & $1.509 \pm 0.031$ \\
& 0.5 & $0.4996 \pm 0.011$ & $0.497 \pm 0.009$ & $0.496 \pm 0.016$ \\
\hline Storage & stability & & & \\
\hline Range & Concentration & Baseline & $\mathbf{1}$ month & $\mathbf{3}$ months \\
& $(\boldsymbol{\mu g} / \mathbf{m l})$ & & & \\
\hline Higher & 20 & $19.11 \pm 0.399$ & $18.87 \pm 0.51$ & $18.53 \pm 0.455$ \\
& 5 & $4.98 \pm 0.139$ & $4.97 \pm 0.183$ & $4.966 \pm 0.185$ \\
Lower & 1.5 & $1.514 \pm 0.018$ & $1.508 \pm 0.022$ & $1.499 \pm 0.026$ \\
& 0.5 & $0.538 \pm 0.038$ & $0.521 \pm 0.021$ & $0.518 \pm 0.03$ \\
\hline
\end{tabular}

*SD: Standard deviation, $\mathrm{n}=3$

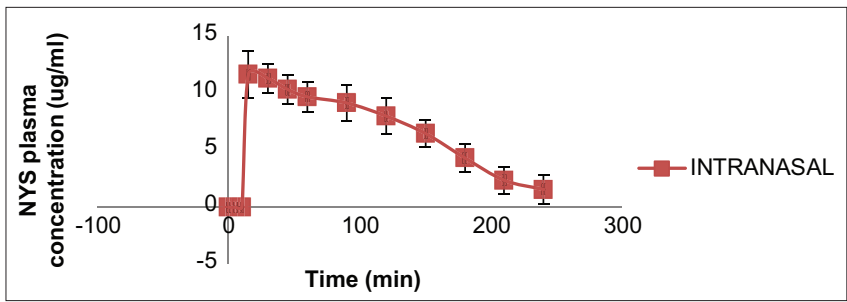

Fig. 2: Plasma concentration time profile of nystatin in plasma post-intranasal administration

\section{CONCLUSION}

In the present study, a rapid and reproducible bioanalytical RP-HPLC method was developed and validated for the assay of nystatin in the plasma of an animal model. The ease of preparation of the mobile phase, the good peak symmetry, and resolution with the added benefit of the comparatively low retention time of the drug facilitate the analysis of a large number of samples over a short span of time. Moreover, the proposed method documented here has been effectively applied to estimate the biopharmaceutical performance of the novel nasal in situ gelling liquid crystalline precursor formulation.

\section{ACKNOWLEDGMENT}

The authors are thankful to Glenmark Limited (Mumbai, India) for providing nystatin as a gift sample.

\section{AUTHORS' CONTRIBUTIONS}

Concept, design, resources, interpretation, and critical reviews - Kazi Marzuka and Dehghan Mohamed Hassan; supervision - Dehghan Mohamed Hassan; and materials, literature search, data collection and/ or processing, and analysis and writing - Kazi Marzuka.

\section{CONFLICTS OF INTEREST}

"The authors declared no conflicts of interest" in the manuscript.

\section{FUNDING}

The authors declare that no funding was received for the conduct of this study.

\section{REFERENCES}

1. Richardson MD, Warnock DW. Antifungal drugs. In: Richardson MD, editor. Fungal Infection. Diagnosis and Management. Oxford:
Blackwell Publishing Ltd.; 2003. p. 29-79.

2. Hamilton-Miller JM. Chemistry and biology of the polyene macrolide antibiotics. Bacteriol Rev 1973;37:166-96.

3. Wasan KM, Ramaswamy M, Cassidy SM, Kazemi M, Strobel FW, Thies RL. Physical characteristics and lipoprotein distribution of liposomal nystatin in human plasma. Antimicrob Agents Chemother 1997;41:1871-5

4. Groll AH, Gonzalez CE, Giri N, Kligys K, Love W, Peter J, et al. Liposomal nystatin against experimental pulmonary aspergillosis in persistently neutropenic rabbits: Efficacy, safety and non-compartmental pharmacokinetics. J Antimicrob Chemother 1999;43:95-103.

5. Offner F, Krcmery V, Boogaerts M, Doyen C, Engelhard D, Ribaud P, et al. Liposomal nystatin in patients with invasive aspergillosis refractory to or intolerant of amphotericin B. Antimicrob Agents Chemother 2004:48:4808-12.

6. Groll AH, Petraitis V, Petraitiene R, Field-Ridley A, Calendario M, Bacher J, et al. Safety and efficacy of multilamellar liposomal nystatin against disseminated candidiasis in persistently neutropenic rabbits. Antimicrob Agents Chemother 1999;43:2463-7.

7. Rank MA, Adolphson CR, Kita H. Antifungal therapy for chronic rhinosinusitis: The controversy persists. Curr Opin Allergy Clin Immunol 2009;9:67-72.

8. Deutsch PG, Whittaker J, Prasad S. Invasive and non-invasive fungal rhinosinusitis-a review and update of the evidence. Med Kaunas Lith 2019;55:319-32.

9. Erdő F, Bors LA, Farkas D, Bajza Á, Gizurarson S. Evaluation of intranasal delivery route of drug administration for brain targeting. Brain Res Bull 2018;143:155-70.

10. Ghadiri M, Young PM, Traini D. Strategies to enhance drug absorption via nasal and pulmonary routes. Pharmaceutics 2019;11:113-32.

11. Sauer B, Matusch R. High-performance liquid chromatographic separations of nystatin and their influence on the antifungal activity. J Chromatogr A 1994;672:247-53.

12. Wilson P, Stewart A, Flournoy V, Zito SW, Vancura A. Liquid chromatographic determination of nystatin in pharmaceutical preparations. J AOAC Int 2001;84:1050-5.

13. Shokraneh F, Asgharian R, Abdollahpour A, Ramin M, Montaseri A, Mahboubi A. A novel high performance liquid chromatographic method for determination of nystatin in pharmaceutical formulations by BoxBehnken statistical experiment design. Iran J Pharm Res 2015;14:43-9.

14. Cione A, Liberale M, Silva P. Development and validation of an HPLC method for stability evaluation of nystatin. Braz J Pharm Sci 2010;46:305-10.

15. ICH Harmonized Tripartite Guideline Validation of Analytical Procedures: Text and Methodology Q2 (R1). Parent Guidelines; 1994. Available from: https://www.fda.gov/regulatory-information/searchfda-guidance-documents/q2-r1-validation-analytical-procedures-textand-methodology.

16. FDA Guidance for Industry: Bioanalytical Method Validation. US Department of Health and Human Services, Food and Drug Administration, Center for Drug Evaluation and Research; 2001. Available from: https://www.fda.gov/regulatory-information/searchfda-guidance-documents/bioanalytical-method-validation-guidanceindustry.

17. Aruna G, Bharathi K, Koganti P. Development and validation of bioanalytical hplc method for simultaneous estimation of cilnidipine and nebivolol in human plasma. Int J Pharm Pharm Sci 2017;10:253-9.

18. Togami K, Fukuda K, Yamaguchi K, Chono S, Tada H. Facile and sensitive HPLC-UV method for determination of nintedanib in rat plasma. Int J Pharm Pharm Sci 2018;6:133-7.

19. Nagavi JB, Gurupadayya B. Simultaneous estimation of clopidogrel and atorvastatin in human plasma using bio-analytical RP-ultra fast liquid chromatographic method. Int J Curr Pharm Sci 2020;7:30-5.

20. Carvalho FC, Campos ML, Peccinini RG, Gremiao MP. Nasal administration of liquid crystal precursor mucoadhesive vehicle as an alternative antiretroviral therapy. Eur J Pharm Biopharm 2013;84:219-27.

21. Michel GW. Nystatin. In: Florey K, editor. Analytical Profiles of Drug Substances. Vol. 6. United States: Academic Press; 1977. p. 341-421. Available from: http:/www.sciencedirect.com/science/article/pii/ S0099542808603494.

22. Llabot JM, Allemandi DA, Manzo RH, Longhi MR. HPLC method for the determination of nystatin in saliva for application in clinical studies. J Pharm Biomed Anal 2007:45:526-30.

23. Groll AH, Mickiene D, Werner K, Piscitelli SC, Walsh TJ. Highperformance liquid chromatographic determination of liposomal nystatin in plasma and tissues for pharmacokinetic and tissue distribution studies. J Chromatogr B Biomed Sci Appl 1999;735:51-62. 